\title{
Penggunaan Aplikasi Komputer dalam Peningkatan Kinerja Guru Sekolah Dasar Negeri 01 Kembangarum Semarang
}

\section{Using Computer Applications to Improve the Performances of Teachers at Public Elementary School of Kembangarum 1 Semarang}

\author{
Enny Dwi Lestariningsih ${ }^{1}$, Testiana Deni Wijayatiningsih ${ }^{2}$, Hascaryo Pramudibyo $^{3}$, \\ Bambang Dalyono ${ }^{4}$, Dwi Ampuni Agustina ${ }^{5}$ \\ ${ }_{1,3,3,5}$ Universitas Terbuka, ${ }^{2}$ Universitas Muhammadiyah Semarang \\ ennydl@ecampus.ut.ac.id, ${ }^{2}$ testiana@unimus.ac.id,
}

Riwayat Artikel: Dikirim 5 Desember 2018; Diterima 26 Mei 2019; Diterbitkan 31 Mei 2019

\begin{abstract}
Abstrak
Sebagian guru di SD Negeri Kembangarum 01 banyak yang masih gagap teknologi terutama mereka yang sudah jadi guru sejak lama atau senior karena selama mereka kuliah, teknologi komputer dan internet belum sebanyak sekarang. Berdasarkan paparan tersebut, semua guru dituntut untuk selalu mengembangkan diri sejalan dengan kemajuan ilmu pengetahuan dan teknologi. Tetapi pada kenyataannya kemampuan mereka cenderung relatif standar hanya mampu mengoperasikan microsoft words saja. Berdasarkan pernyataan tersebut, tim pengabdi kami memfokuskan pengabdian masyarakat pada pemanfaatan teknologi komputer pada guru SDN 01 Kembangarum Semarang yang berjumlah 21 orang. Adapun metode pelatihan yang dilakukan menggunakan metode ceramah, praktek, dan evaluasi kepuasan peserta pelatihan. Dari program pelatihan pengabdian masyarakat tersebut dihasilkan peningkatan kemampuan mengoperasikan microsoft words, power point, microsoft excel, pelatihan membuat email, dan pelatihan mendaftar website di wordpress. Para guru menjadi termotivasi untuk lebih menggunakan power point, dan website gratis sebagai media pembelajaran dan penghitungan dalam excel untuk mengevaluasi penilaian siswa baik ulangan harian, tugas, UTS, atau UAS.
\end{abstract}

Keywords: aplikasi komputer, kinerja guru, sekolah dasar.

\begin{abstract}
Some teachers at Public Elementary School of Kembangarum 1 are technologically illiterate, primarily the senior ones, for when they were students the technology was not as high as it is now. Based on that, all of the teachers are asked to always develop themselves in line with the advancement of science and technology. I fact, their abilities are relatively standard, only able to operate Microsoft Word. Therefore, we conducted a community service focusing on utilizing computer technology for 21 teachers at Public Elementary School of Kembangarum 1 Semarang. Methods used were lecture, practice, evaluation on satisfaction, and training. Results of the community service showed that the ability to operate Microsoft Word, Power Point, and Microsoft Excel improved. Trainings on how to create an email and register a website on Wordpress were also given. The teachers were more motivated to use Power Point application and free-of-charge website as learning and calculating media in excel in order to evaluate the students' assessments in both daily tests, assignments, mid-term test, and post-term test.
\end{abstract}

Keywords: computer application, student performance, elementary school. 


\section{PENDAHULUAN}

Teknologi di Indonesia mengalami perkembangan yang pesat di berbagai bidang termasuk teknologi komputer dan internet yang secara langsung menuntut dunia pendidikan untuk bertindak secara nyata dalam menyesuaikan diri mengikuti perkembangan teknologi. Dalam hal ini guru sebagai ujung tombak dunia pendidikan, maka untuk menunjang pekerjaannya yang sekarang sudah menjadi profesi berdasarkan undang undang guru dan dosen. Semua guru harus belajar teknologi internet dan komputer.

Selanjutnya, guru memiliki profesi dengan tugas utamanya adalah mendidik, merencanakan pembelajaran, mengajar, membimbing, mengarahkan, melatih, menilai, dan mengevaluasi peserta didik. Mulai dari PAUD (Pendidikan Anak Usia Dini) sampai pendidikan menengah. Selain itu, guru juga harus memiliki kompetensi pedagogik dan kompetensi profesional. Oleh karena itu, untuk menunjang hal tersebut harus didukung oleh penguasaan teknologi terbaru terutama teknologi komputer dan internet.

Berdasarkan pengamatan pengabdi, sebagian guru banyak yang masih gagap teknologi terutama mereka yang sudah jadi guru sejak lama atau senior karena selama mereka kuliah, teknologi komputer dan internet belum sebanyak sekarang. Kalau sekarang penggunaan internet murah juga dan sudah menyebar ke pelosok desa. Berdasarkan paparan tersebut, semua guru dituntut untuk selalu mengembangkan diri sejalan dengan kemajuan ilmu pengetahuan dan teknologi. Ada beberapa alasan mengapa guru wajib mengembangkan diri yaitu:

1. Guru sebagai perencana pembelajaran, dalam tugasnya guru harus membuat administrasi pembelajaran berupa program tahunan, program semester, pengembangan silabus, membuat RPP (Rancangan Program Pembelajaran) yang kesemuanya disebut dengan perangkat pembelajaran. Hal ini tentu harus disajikan secara otentik terdokumentasi maka berdasarkan hal tersebut setiap guru harus bisa mengetik dengan komputer minimal program Microsoft Office Word. Memang ada sebagian guru yang dengan alasan sibuk mereka tidak sempat membuat perangkat pembelajaran sehingga perangkat pembelajaran cukup copas punya orang punya teman sesama guru tapi hal ini tentunya sangat tidak baik karena kalau orang lain yang membuat perencanaan kadang tidak sesuai dengan karakter peserta didik kita. Sekarang sudah banyak penyedia perangkat pembelajaran secara online maupun gratis yang tersedia di internet guru-guru atau calon guru bisa unduh dengan gratis tapi itu semua hanya sebagai bahan perbandingan saja.

2. Guru bertugas membimbing peserta didik di kelas, di laboratorium atau bengkel kerja terhadap peserta dalam pembelajaran. Dalam penyampaiannya bila guru menguasai komputer maka bisa menggunakan software untuk presentasi yaitu Microsoft Office Power Point seharusnya bahan presentasi juga dibuat dan disiapkan guru sendiri. Karena dalam pembelajaran guru minimal harus menyampaikan tujuan pembelajaran atau tujuan pembelajaran harus diinformasikan kepada peserta didik di awal pembelajaran.Lebih jauh lagi menyampaikan konsep dengan Microsoft Office Power Point akan lebih menarik bila dibanding dengan guru menuliskannya di papan tulis yang masih menggunakan spidol dan white bord dan sebagian besar sekolah di tanah air masih banyak yang menggunakan papan hitam dan kapur.

3. Guru memiliki tugas menilai dan mengevaluasi hasil pembelajaran. Evaluasi memiliki fungsi sebagai umpan balik untuk memberi masukan dalam langkah selanjutnya. Pemberian nilai kepada peserta didik harus sesuai dengan hasil yang mereka dapat hal ini 
selain merupakan reward juga akan memberi motivasi peserta didik untuk terus belajar dan berkompetisi secara sehat. Maka dengan menggunakan komputer misalnya microsoft office excel perhitungan nilai akan lebih mudah dibanding dengan cara manual.

Penggunaan komputer sebagai alat mengetik untuk membuat administrasi adalah tentu sebagai teknologi minimal yang harus dikuasai oleh guru maka untuk lebih jauh lagi ditambah dengan internet di mana guru bisa membuat email atau mendownload jurnal penelitian tindakan kelas untuk menulis dalam rangka mengembangkan ilmu pengetahuannya dan menyuarakan opini yang bisa dibaca oleh umum, oleh sesama guru atau membuat tugas materi pembelajaran untuk peserta didik.

Berikut kami sajikan gambar kegiatan guru dalam pembelajaran di kelas.

Gambar 1.

Contoh guru sedang mengajar di kelas

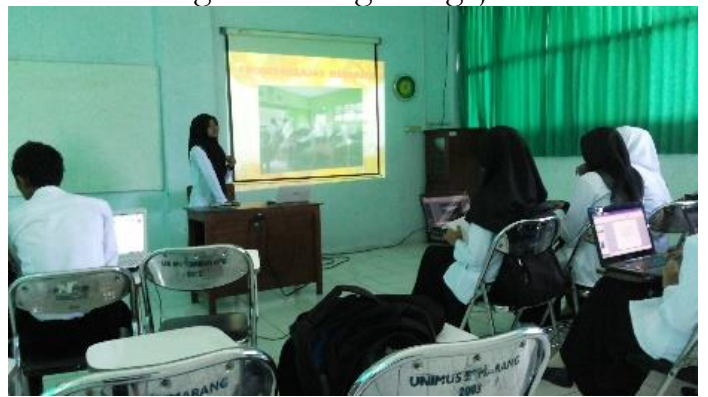

Berdasarkan paparan tersebut, pengabdian kami berpusat pada pelatihan keterampilan komputer dan internet untuk pembelajaran di kelas pada guru Sekolah Dasar Negeri 01 Kembangarum yang berjumlah 18 orang.

Berdasarkan penjelasan di atas, kami memfokuskan pada peningkatan keterampilan teknologi komputer dan internet yang lokasinya berjarak lebih kurang lebih $10 \mathrm{~km}$ dari Kantor UPBJJ Universitas Terbuka Semarang. Selain itu, kami sebagai tim pengabdi juga akan membantu meningkatkan profesionalisme guru untuk berkembang sesuai perkembangan IPTEKS melalui berbagai pelatihan teknologi komputer dan internet. Oleh karena itu, kelompok guru di SDN Kembangarum 01 layak dijadikan sebagai lokasi pengabdian masyarakat untuk peningkatan profesionalisme guru di bidang teknologi komputer. Potensi unggulan atau masalah di masyarakat adalah guru di SDN Kembangarum 01 rata-rata belum menguasai teknologi komputer dan internet, maka perlu dilakukan pelatihan teknologi komputer yang dikolaborasi dengan bahasa Inggris sederhana sehingga profesionalisme guru dalam bekerja menjadi meningkat.

Sebagai mitra dalam kegiatan pengabdian masyarakat ini adalah kelompok guru Sekolah Dasar di SDN Kembangarum 01 Kecamatan Semarang Barat Kota Semarang yang berjumlah 18 orang (Kesediaan mitra bekerja sama dengan Tim pengabdian masyarakat Universitas Terbuka UPBJJ Semarang terlampir). Dampak keberadaaan mitra terhadap lingkungannya adalah memotivasi dan menuntun guru untuk lebih paham dengan teknologi komputer dalam aplikasi profesi guru.

Pelatihan teknologi komputer di SDN Kembangarum 01 meliputi pelatihan microsoft words, excel sederhana, membuat power point, mengunduh artikel jurnal online, dan membuat email.

Adapun permasalahan yang selama ini dihadapi guru adalah sebagai berikut;

1. Kurangnya contoh nyata bahwa peserta didik selain diajarkan moral dan karakter bangsa yang baik juga belajar teknologi yang harus diberi contoh dalam elaborasi serta eksplorasi terhadap ilmu pengetahuan oleh guru jadi sebelum peserta didik maka gurunya harus mahir. Karena pembelajaran karakter perlu diberi contoh nyata dari orang yang lebih dewasa oleh orang tua atau guru seperti yang sudah dibahas dalam menanamkan karakter melalui contoh.

2. Karena adanya pemetaan kompetensi guru mulai tahun 2012 diadakan uji kompetensi guru yang dilakukan secara 
online

melalui

situs

ukg.kemdikbud.go.id.

3. Kurangnya penguasaan guru terhadap teknologi komputer dan internet yang menunjang kinerja.

4. Penguasaan guru terhadap IT turut menyumbang kelancaran pembelajaran. Karena sekolah sudah banyak yang menggunakan pembelajaran online.

Dari permasalahan yang dihadapi mitra tersebut maka Tim IbM dengan mitra menentukan prioritas yang harus ditangani, yaitu:

1. Peningkatan kemampuan dalam mengoperasikan microsoft office, excel sederhana, browsing artikel jurnal online.

2. Peningkatan kemampuan dalam membuat Power Point

3. Pembuatan panduan teknologi komputer praktis dan mudah diterapkan.

\section{Metode}

Pelatihan ini menggunakan metode, diskusi, ceramah, praktek, dan evaluasi kepuasan peserta pelatihan. Ceramah dan diskusi merupakan metode yang digunakan ketika tim pengabdian masyarakat memberikan pelatihan komputer yang dilaksanakan selama 4 bulan. Metode praktek merupakan metode yang digunakan ketika para guru mempraktekkan aplikasi computer dalam kegiatan di sekolah. Metode evaluasi merupakan metode yang digunakan untuk mengevaluasi kepuasan peserta pelatihan yakni para guru SDN 01 Kembangarum Semarang.

\section{Hasil Dan Pembahasan}

Pelaksanaan pengabdian masyarakat pada kelompok guru SD Negeri Kembangarum 01 berjalan sesuai dengan perencanaan dan terlaksana dengan lancar. Pengabdian masyarakat dilaksanakan tanggal 2 September 2017 yang dimulai jam $7.30 \mathrm{~s} / \mathrm{d}$ 16.00 untuk kegiatan pelatihan komputer (excel, microsoft words, dan pendaftaran website di wordpress.com) dan tanggal 12 September 2017 untuk pelatihan power point. Setelah itu berlanjut dengan monitoring aplikasi pelatihan komputer pada kegiatan guru sehari-hari yang dilaksanakan pada hari Sabtu sebanyak 4 kali monitoring.

Berikut kami sajikan dokumentasi program pengabdian yang terangkum pada gambar bawah ini.

Gambar 2.

Pembukaan Pelatihan Komputer

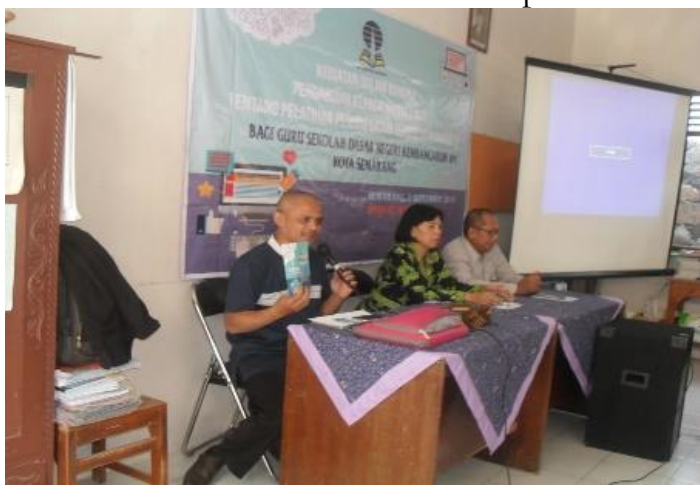

Pembukaan pelatihan komputer dihadiri sekitar 20 peserta yang terdiri dari beberapa guru, kepala sekolah, tenaga administrasi, dan tenaga kebersihan sekolah. Dalam acara ini, tim pengabdi memberikan arahan bentuk dan juknis pelatihan dengan menggunakan buku panduan yang telah dicetak dan di-ISBN sesuai dengan standar perpustakaan nasional. Buku pelatihan tersebut meliputi 50 halaman dengan model cetakan A5. Adapun sambutan para guru SD Negeri 01 Kembangarum sangat antusias karena mereka cenderung dapat meningkatkan pemahaman dalam mengoperasikan komputer.

Kemudian pada hari kedua tim pengabdi lebih memperdalam pemahaman komputer dengan cara praktek membuat email, website, dan menyusun laporan nilai dalam bentuk soft file dalam microsoft excel.

Selanjutnya setelah pelatihan, tim pengabdi melakukan monitoring pengabdian selama empat kali. Dalam monitoring ini, tim pengabdi mengecek kembali penggunaan komputer dalam adminsitrasi sekolah dan rancangan mengajar. 
Setelah itu, tim pengabdi memberikan kenang-kenangan kepada pengelola yakni Bapak Agus Ngaderiyanto atas kerjasama dan antusiasnya sehingga melancarkan program pengabdian ini.

Gambar 3.

Proses Pelatihan

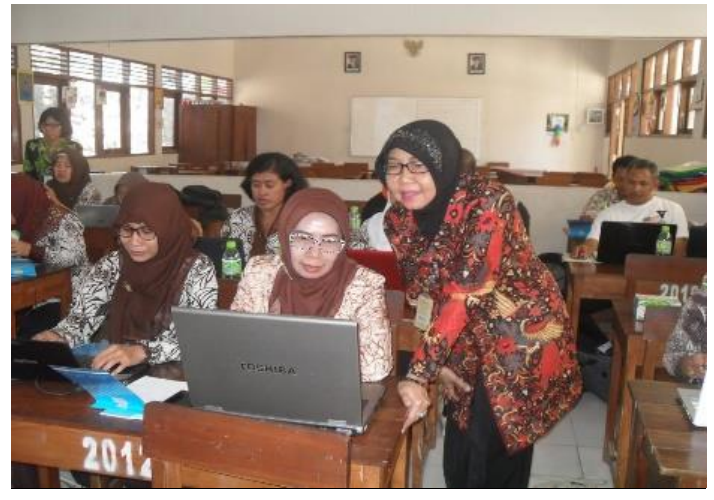

Gambar 4.

Proses Monitoring

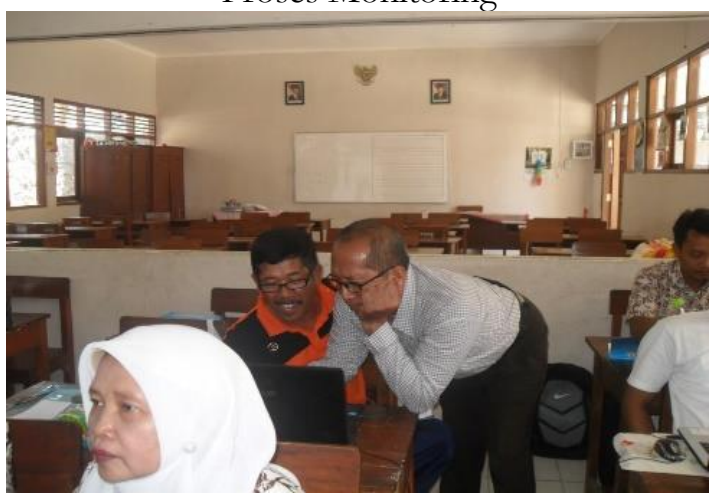

Gambar 5.

Penutupan Pelatihan

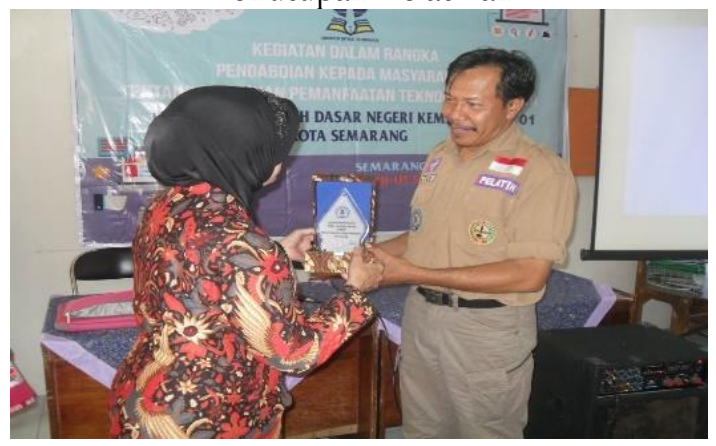

Kegiatan pengabdian masyarakat ini sudah terlaksana dengan baik yakni pelatihan komputer untuk guru SD. Hasil yang dicapai adalah para guru-guru SD di SD Negeri 1 Kembangarum merasa sangat puas dengan penyajian materi buku panduan dengan persentase capaian 28\% dan mereka merasa puas dengan capaian $72 \%$. Selanjutnya mereka juga sangat puas $22 \%$ dan merasa puas $78 \%$ dengan cara dan teknik pelatihan tim pengabdi. Kemudian hasil persentase penyajian materi pelatihan bagi peserta guru-guru SD mencapai tingkat sangat puas $17 \%$ dan puas $83 \%$. Sedangkan peserta pelatihan juga merasa sangat puas $38 \%$ dan puas $62 \%$ untuk program pelatihan yang disajikan oleh tim pengabdi. Selanjutnya, peserta pelatihan juga merasa sangat puas $26 \%$ dan puas $74 \%$ untuk pelayanan tim pengabdian kami. Paparan hasil kuesioner kepuasan mitra tersebut di atas, didukung oleh hasil wawancara dengan beberapa guru secara acak setelah mereka mengaplikasikan excel, power poin, website, dan microsoft words dalam kegiatan administrasi baik perencanaan pembelajaran, laporan nilai, menganalisis nilai, dan memberikan tugas pelajaran. Mereka mengalami perubahan yang drastis karena lebih mudah menyelesaikan pekerjaan dengan bantuan computer khususnya dalam penilaian dan pembelajaran.

Adapun hambatan yang dihadapi dalam pelaksanaan pengabdian ini adalah kurangnya kesadaran para guru-guru SD untuk mau belajar menggunakan komputer dan meluangkan waktu untuk menggunakan program komputer dalam pengajaran mereka di kelas. Namun, pada akhirnya sebagian besar sangat bersemangat ketika mengetahui dan mempelajari program aplikasi komputer yang membantu pembelajaran di kelas bersama tim pengabdian kami.

Adapun cara penanggulangannya adalah dengan melakukan pendekatan kepada setiap peserta pelatihan ketika pelatihan berlangsung untuk mendukung dan memberikan semangat bahwa komputer sangat penting dalam kesuksesan pembelajaran di kelas. Selain itu, memonitoring aplikasi penggunaan komputer seminggu sekali untuk 
mendukung agar aplikasi komputer digunakan dalam aktivitas sehari-hari.

\section{KESIMPULAN DAN SARAN \\ Kesimpulan}

Berdasarkan hasil kegiatan pengabdian masyarakat ini, pengabdi dapat menarik kesimpulan sebagai berikut:

1. Pengabdian masyarakat teknologi komputer pada guru SDN 01 Kembangarum Semarang diterima dengan baik oleh pihak mitra dan mencapai tujuan yang sudah direncanakan sebelumnya.

2. Para guru SD di SDN 01 Kembangarum merasa puas dengan pelayanan tim pengabdi dengan persentase capaian $74 \%$.

3. Dari keseluruhan paparan di atas, program pengabdian kami sudah teraplikasi dengan baik serta selalu dimonitor perkembangannya agar terus berjalan dan berkembang baik kemampuan dalam mengoperasikan komputer, pemanfaatan komputer sebagai sarana dan media pengajaran, serta penggunaan excel dan website pada administrasi penilaian dan sebagai media di pembelajaran di kelas.

\section{Saran}

1) Bagi Guru SD

Para guru hendaknya selalu berlatih untuk meningkatkan kemampuan mengoperasikan komputer dan memanfaatkan program komputer untuk pembelajaran di kelas.

2) Bagi Kepala Sekolah

Pengadaan pelatihan yang berhubungan dengan peningkatan mutu pembelajaran di kelas sangat diperlukan oleh para guru SD guna pengembangan profesi dan kemampuan pengajaran mereka. Oleh karena itu, pihak pengelola sekolah dapat memberikan saram latihan peningkatan kmpetensi guru khususnya penggunaan komputer dalam pembelajaran dan administrasi sekolah.

\section{DAFTAR PUSTAKA}

Miarso, Y. (2011). Menyemai Benih Teknologi Pendidikan. Jakarta: Prenada Media Group.

Moeliono, A. M. (1990). Kamus Besar Bahasa Indonesia. Jakarta: PT. Balai Pustaka.

Moleong, L. J. (2007). Metodologi Penelitian Kualitatif Edisi Revisi. Bandung: PT Remaja Rosdakarya.

Mulyasa, E., \& Mukhlis. (2007). Standar Kompetensi dan Sertifikasi Guru. Remaja Rosdakarya.

Niarsa, A. (2013). Studi Kompetensi Guru Dalam Memanfaatkan Media Pembelajaran Berbasis Teknologi Informasi Dan Komunikasi (TIK) DI SD Negeri 01 Ledok Kecamatan Sambong Kabupaten Blora (Skripsi, Universitas Negeri Semarang).

RI, M. P. N. (2007). Peraturan Menteri Pendidikan Nasional Nomor 16 Tahun 2007 Tanggal 4 Mei 2007 Tentang Standar Kualifikasi Akademik Dan Kompetensi Guru.

Putra, D. (2000). Belajar dan Panduan Praktis Microsoft Windows 95/98/2000, Word 2000, Excel 2000: Standar Aplikasi Komputer Pemula. Surabaya: Indah.

Rustad, Supriyadi dan Sugiyanto. (2007). "Implementasi Information and Communication Technology (ICT) dalam Pembelajaran Inovatif', dalam Panduan dan Materi Workshop Pengembangan Pembelajaran Inovatif.

Setiawan, D., dkk. (2009). Komputer dan Media Pembelajaran. Jakarta: Universitas Terbuka.

Sudibyo, L. (2011). Peranan dan Dampak Teknologi Informasi dalam Dunia Pendidikan di Indonesia. Widyatama, 20(2), 175-185.

Aulia, T. R. N. (2006). Himpunan Perundang-undangan Republik Indonesia tentang Sistem Pendidikan Nasional. Bandung: Nuansa Aulia.

Triwahyuni, T. \& Kadir, A. (2007). Power Point 2007: Trik dan Tip Power Point dari Dasar Sampai Tingkat Profesional. Yogyakarta: Andi Offset. 
Nasional, D. P. (2005). Undang-Undang Nomor 14 Tahun 2005, Tentang

Guru dan Dosen. Jakarta: Depdiknas. 